\title{
EXPLORING THE NEED FOR A NEW PARADIGM IN ENGINEERING MANAGEMENT AND THE DECISION-MAKING PROCESS IN TECHNOLOGY-BASED ORGANISATIONS
} pages: $7-21$

\author{
SIMON P. PHILBIN ${ }^{\circledR}$ DONALD KENNEDY ${ }^{(1)}$
}

\begin{abstract}
A B STR A C T
Engineering management and engineering projects are subject to greater levels of uncertainty and complexity as part of the current dynamic and competitive industrial environment. Engineering managers need to navigate the arising challenges and consequently gain access to effective decision-making processes. Engineering education has a clear role to play here. However, formal education in quantitative methods is only part of the solution - engineers and engineering managers should also have access to a broader set of skills and knowledge to be effective in the industrial landscape. Therefore, we now need a new paradigm for engineering management and the decision-making process. This article draws on supporting material from the literature and the insights gained from a series of industrial cases using the participatory action research method and a process of inductive reasoning to allow synthesis of generalised propositions that are linked to the industrial cases and antecedent factors from the literature. The findings lead to a set of areas that require further development to support engineering managers to be more effective when dealing with increasing levels of uncertainty and complexity. This includes a number of areas, which are as follow: the need for engineering managers to have enhanced professional skills and knowledge; the importance of experience-based judgement; effective knowledge management; supportive leadership and overall organisational culture; and a holistic approach to decision-making. The research study has practical relevance to engineering management practitioners working in industrial companies to support self-evaluation and professional development. The findings are also pertinent to academic researchers seeking to evaluate decision-making models as part of extending the current understanding of the field of engineering management in technology-based organisations.
\end{abstract}

engineering management, engineering projects, decision-making, new paradigm

10.2478/emj-2020-0024
Donald Kennedy

Freerange Buddy Publications, Canada ORCID 0000-0002-9156-0833

Corresponding author: e-mail: don@donkennedy.ca

Simon P. Philbin

London South Bank University, United Kingdom ORCID 0000-0001-8456-3342

\section{INTRODUCTION}

As is the case in so many fields, the state of engineering management practice is undergoing changes in this age of uncertainty and especially in the context of the pandemic caused by COVID-19 (Baker et al.,
2020). The main driver for these changes has previously included high employee turnover and changes to organisations with little historical precedence to draw from - the pandemic is simply exacerbating this situation even further. The current wave of tech-

Philbin, S. P., \& Kennedy, D. (2020). Exploring the need for a new paradigm in engineering management and the decisionmaking process in technology-based organisations. Engineering Management in Production and Services, 12(4), 7-21. doi: $10.2478 / \mathrm{emj}-2020-0024$ 
nological developments, such as those associated with Industry 4.0 (Xu et al., 2018) and the wider area relating to digitalisation (Parviainen et al., 2017) as well as the increasing interconnectedness of technologies is leading to greater levels of complexity, e.g. via system-of-systems (Lucia et al., 2016). Engineering managers are required to handle this complexity and uncertainty, and in this context, it is vital that engineering managers are equipped with effective decision-making skills. Moreover, as new technology-driven business models are adopted along with flatter organisational structures, it is increasingly the case that engineers are expected to transition into managerial and leadership roles earlier in their careers (Nittala \& Jesiek, 2018). Some researchers argue that in order to cope with a higher level of complexity, organisational structures must be simplified and this can be considered through balancing the fit between simple structural solutions, complex workforce arrangements and the complex environment (Tworek et al., 2019). But from a more historical perspective, it can also be observed that throughout the time from when Taylor (1911) and Fayol (1918) developed management as an academic discipline up until the present day, there have been ongoing debates as to what actions are effective and how managers can achieve desired outcomes, i.e. the role of decision-making (Elbanna, 2006). Certain researchers proposed strategies that have gained pockets of popularity, but others question the validity of the findings.

Koontz (1960) compared understanding the competing schools to working through a "theory jungle". For example, should management dictate policy to assure best practice as stressed by Taylor (1911), or will improved performance be achieved by giving workers the freedom to determine their own best methods as indicated by the Hawthorne Experiments (Roethlisberger \& Dickson, 1939). Moreover, in 1982 McGuire outlined how prevailing management theories change over time, but there is seldom a strong contender for a majority view and when there is one it does not last for very long. Rossler and Kiser (2002) lament that there is some key element missing from our understanding that might account for why certain strategies work in some situations and fail when applied in what appear to be similar circumstances elsewhere. Despite the seemingly lack of a cohesive body of knowledge, there are some hints in prior works that indicate a need for a paradigm shift (see the work of Koschmann (1996) for a comprehensive discussion on this theoretical perspective), and consequently, this article provides an exploratory analysis of this line of enquiry. Therefore, we propose that there is a pressing need for a new paradigm to be adopted for engineering management and the decision-making process.

The structure of this article is as follows. After the introduction is the second section that provides the literature review, and the third section describes the method adopted in the research study. The fourth section includes a discussion of industrial case studies. The fifth section is based on the synthesis of the research findings towards a new paradigm for engineering management and decision-making. This is followed by the conclusions and future work.

\section{LITERATURE REVIEW}

\subsection{ENGINEERING MANAGEMENT PARADIGM}

This paper is directed at the field of Engineering Management as opposed to management in general. It is acknowledged that there is no clear division between the two disciplines that has been universally agreed upon (Lannes, 2001), but it should be noted that this research study is directed at Engineering Management in particular. To draw from one of the pioneers of Engineering Management as a recognised field, Sarchet (1989) offered that Engineering Management is specialised towards organisations dealing with processes and products of a technical nature. These organisations would have a notable contingent of their labour force employed as engineers. The narrower focus for this study is due to the proficiencies, backgrounds, and certifications of the authors. Although the topics may be applicable to the management field in general, the case studies, cited literature, and outcomes specifically deal with technical elements. The qualifications of the authors specifically to Engineering Management require a cautionary disclaimer that the applicability to management in general would require others to verify.

The concept of paradigms to define the collective understanding of a specific scientific field is attributed to Kuhn (1977). Discussions on the applicability of defining management, or Engineering Management, as science have shown such an approach to be problematic. McGuire (1982) proposed that taking an overarching view of the tracks within management theory does not yield a unified position. He also noted that the application of the existing tools often falls short of helping a manager deal with the required 
tasks. The lack of explicit consensus on fundamental principles within the management of knowledge workers is highlighted by Hazlett, McAdam, and Gallagher (2005) who contend the current state of the field would be best defined as a "pre-science" in Kuhn's taxonomy. Kennedy and Nur (2012) warn that focusing on prescriptive task definitions for knowledge workers creates inefficiencies in execution, but that high employee turnover appears to be driving organisations down that path. There is evidence that management practitioners would benefit from a more unified collection of theories, and many of the existing frameworks may fall short of the intent to aid managers in decision-making. This research study intends to highlight factors that may provide significant benefit to academics in developing tools to guide future practitioners. The lack of an existing unified body of knowledge hinders the presentation of modifications to improve understanding. This work intends to spur investigations in a direction that may prove highly beneficial to engineering and technology-based organisations going forward.

\subsection{HistoricAl OVERVIEW}

Frederick Herzberg is one of the major influencers in the development of management theory (Balzer \& Smith, 1990). Much of his research was devoted to improving the quality of work and improving organisational performance as a result. Herzberg recognised that managers and academics looked to him for guidance. However, Herzberg (1966) warned that following his advice would not automatically result in the quantum shift in outcomes that his audience may be seeking. He acknowledged that the financial success of organisations is mostly determined by often one-time strategic decisions made relating to elements such as the physical location, engineering facility design and marketing strategy adopted. W. Edwards Deming is often credited with leading the move to focus on modern quality principles, including increasing the workers' ability to self-determine their processes (Phelps, Parayitam \& Olson, 2007). Despite Deming's focus on quality and stressing the folly of measuring employee performance, he stated that the most important decisions determining organisational performance could be the hiring of talented workers.

Herzberg did not devote attention to the factors he listed as being the most critical because he acknowledged that these decisions are typically made long before managers find themselves in charge of their departments. He focused on the issues that managers typically have control over. Similarly, Deming did not write extensively on the hiring process and finding these talented people. Like Herzberg, Deming viewed the turnover of employees as so low that managers did not have much influence on who is actually on their team (Gabor \& Tarrant, 1990). Furthermore, in Deming's time, lifelong employment at the same company was realistically expected by workers and managers. Therefore, in Deming's view, there was little point in measuring performance differences in workers since there was very little managers could do about the findings. These examples of the focus of Deming and Herzberg are offered to provide a possible explanation for the lack of study on those factors they recognised to be most influential on organisational performance.

Taylor's work supports the ideas of Deming and Herzberg that worker performance is mostly influenced by the workplace they occupy, which is analogous to the contingency theory of management, i.e. the design and implementation of control systems is dependent on the context and environment of the organisational setting (Fisher, 1998). Taylor proposed that it is the duty of management to provide the optimum tools to allow the workers to excel. Deming stated that measured variations in worker performance are most likely to be rooted in the variances in the physical system the worker occupies (Carson, Cardy \& Dobbins, 1991). During the Hawthorne Experiments, Roethlisberger \& Dickson (1939) recorded an analysis of the top performers as defined by the measures used by management. They were very surprised to find a negative correlation between talent (as measured by elements such as IQ and aptitude tests) and performance. The explanation given was that the reward system discouraged the better-skilled workers from achieving their full potential. All workers demonstrated a reluctance to push themselves to the maximum and the best effectively held back the most. The workers' explanation for this was that management was not aligned with supporting top performance. The most skilled workers reported that management tended to thwart their efforts and that they were generally unrecognised when they did put in any extra effort. That this was observed more than 80 years ago, hints that an opportunity was identified and appears to have had little attention paid to it over that time.

\subsection{HOW WORK HAS CHANGED}

To quantify the order of magnitude in worker performance, Tom Peters (2004) reported that a top 
worker performing manual tasks might be three times better than an average, competent worker. Recognising the shift towards increasing numbers of people performing tasks with non-tangible outputs, Drucker (1959) coined the term "knowledge worker" to provide insights on how to manage such work. Peters (2004) proposed that the potential with knowledge work productivity improvements is significantly greater than manual, tangible outputs. Top knowledge workers are around seven times more productive, given that knowledge workers can eliminate unnecessary steps and still achieve the desired results. When combined with the reductions in team communication paths and supervision requirements coming from a drastic reduction in labour, a highly effective team can potentially achieve better results than a large complex organisation due to possessing a higher level of per-worker output. Moreover, Kennedy (2010) provided several examples of observed situations where these levels of output by top performers were achieved for both manual and knowledge work. In one case presented by Kennedy, not only could the one worker equal the quantity of output of six peers, but the client-reported quality of work was also superior.

There are pockets of literature examining the critical nature of top performers to organisational survival. These individuals are seen to be scarce enough that an organisation may not be able to find a suitable replacement should they lose key talent (Aguinis, Gottfredson \& Joo, 2012). In what is widely considered the project management "bible" (Zhang, Kitchenham \& Jeffery, 2007), Kerzner outlines how top performance comes when highly competent people are allowed to deviate from the prescriptive processes sanctioned by upper management (Kerzner, 2017). This is in contrast with Taylor's "one best way" of performing tasks that should be specified by management for the workers to follow. Taylor's strategy will likely be satisfactory for the typical worker, manual or knowledge focused. If the rare highly skilled knowledge worker is a reality, potentially game-changing results will only be realised if these workers can deviate from the way their peers are instructed to perform.

Looking at current trends, it appears the level of automated processes will increase, and the managerial toolbox previously developed under a system heavily reliant upon manual, tangible outputs per worker will decrease in suitability for future organisations (Kennedy \& Philbin, 2018). As noted in the introduction, technological developments associated with Industry 4.0 (Xu et al., 2018; Krykavskyy et al., 2019; Vetrova et al., 2020; Nwaiwu et al., 2020) and the wider area of digitalisation (Parviainen et al., 2017; Afonasova et al., 2019; Siderska, 2020) can create a system highly sensitive to the decisions of a single worker. The increasing interconnectedness of technologies leads to greater levels of complexity as demonstrated by increasing interest in concepts such as system-of-systems (Lucia et al., 2016; Philbin, 2008). The potential for an increased impact on performance by single individuals is more significant to managers given the global trends for much higher employee turnover than that experienced by early researchers (Rana et al., 2009).

Despite the importance of individuals in the organisation as discussed by Herzberg, Deming and others, they spent little time discussing employee selection because of the expectation of lifelong employment for the worker (Wolff, 2008). To be better prepared for future workplaces, managers should therefore be equipped with the tools to capitalise on the dual impacts of greater sensitivity to the performance from individual workers and the high turnover of employees providing much higher incidences of opportunities than expected by the earlier researchers in management.

\subsection{RECOGNISING THE IMPACT OF TOP PER- FORMERS}

The rarity of those with game-changing skills has been broached by Fox (2009), when looking at mutual fund managers. Fox contends that any detailed analysis of fund performance yields that differences in managers over time cannot be shown to be anything more than random chance. Managers who have fund returns above average one year are as equally likely statistically to be below average the next as those who finished below average the prior year. As well, gross performance above the market indices is typically less than the management fees charged for the work.

This has given rise to the increase in exchangetraded index funds (ETFs) at the expense of investment in mutual funds. However, Fox notes that there will be those rare managers who are worth their fees and who will adapt their strategies to match conditions to beat random performance defined by the indices. Fox provides Warren Buffett as the most famous of these. The scarcity of these people makes it very difficult to find them among the population of their peers who do not secure statistically significant results. 
It appears that the nature of the situational understanding required for these talented people to make the decisions with long-lasting impacts is not deep or overly complicated from a technical perspective. As with the example of mutual fund managers, it is more common than it should be for senior managers to not know who is providing higher-quality information. Upton (1998) provided the case in the 1980s when Kodak considered improving their chemical processes. Feedback from many employees at lower levels varied about the benefits to the proposed upgrade. The manager burdened with the final decision, ultimately decided to cancel the project in what was viewed by his superiors as a bold move. This allowed rival Fujifilm to hire Kodak's now unneeded technical experts and establish a modern plant based on the concepts of the scrapped Kodak upgraded production facility. The impact on Kodak's business resulted in losing $10 \%$ of the domestic U.S. market share within a few years with a corresponding uptake by Fujifilm. This highlights how a single decision can have billions of dollars in impact (Gavetti, 2004) and how a different person in that position could make the opposite decision given the same evidence.

In another case of when a company's swings in fortune result from a few decisions, Xerox provides evidence of how individuals can greatly impact performance. In 1999, new CEO Thoman attempted to take Xerox away from their roots as an equipment manufacturer to a provider of services. After a $90 \%$ drop in market capitalisation to under USD 300 million, Thoman was let go (Chesbrough, 2002). New CEO Anne Mulcahy returned Xerox to a focus on manufacturing and reversed the downward spiral in earnings and investor trust (Slocum, 2006). Xerox is again a solid, consistently profitable company with a market capitalisation now over USD 8 billion. The technology sector has several further high-profile examples of where decisions were taken that had a profound impact on the company - in some cases, a positive impact, and in others, a negative one. In the widely reported case for the previous market leader for video rentals, Blockbuster, once had the opportunity to acquire a major share of the startup Netflix (Sim, 2016). At the time, the CEO decided not to pursue the acquisition; within a short period of time thereafter, Blockbuster became a bankrupt company, completely losing its market dominance and being swept aside by the rapid success and growth secured by Netflix. The CEO's decision, in this case, having a catastrophic outcome for Blockbuster employees and shareholders. In terms of management theory, this is also an excellent example of the impact of creative destruction (Diamond, 2019), where the new technology-driven business model of Netflix disrupted the marketplace and ultimately led to the demise of Blockbuster.

The above examples are provided to demonstrate how individuals make decisions that are difficult to judge objectively on quantitative analysis, are not overly technical, but can have a significant and longterm impact on an organisation's performance. The authors contend that there are opportunities for these types of decisions at most levels and how they are generally not noticed by management.

\section{RESEARCH METHODS}

The method adopted in this research study is based on the process of inductive reasoning to identify specific instantiations that can be used to derive more generalised conclusions (Ketokivi \& Mantere, 2010). The nature of knowledge work limits the viability of traditional deductive experimentation to arrive at a "one best method" to direct employees (Mintzberg, 1973). Mintzberg established a detailed taxonomy of possible research methods. Mintzberg demonstrated how most are difficult to use in a managerial setting and still provide reliable results that tie to the research topic. Selecting a research method becomes a process of eliminating those from the taxonomy that are not viable until few remain. As an illustrative example from this research, a quantitative analysis of a survey, according to Mintzberg, would require a thorough understanding of the complex system prior to the development of survey questions that could add insight. Mintzberg suggests that once the level of understanding is adequate for developing such surveys, the increased understanding from such a process is much lower than that acquired from the initial insights obtained through observation. We direct the reader to Mintzberg's book for a detailed analysis of further information on the selection of research methods if there is uncertainty on why an alternative research method was not selected here. The cases used for this paper occurred over several decades. The synthesis of the proposition offered developed from an initial idea stemming from reflections upon similar occurrences and returning to the cases presented here to provide the evidence that supports the position of the authors.

The main areas, as part of the methodological scheme for the research study, are depicted below 


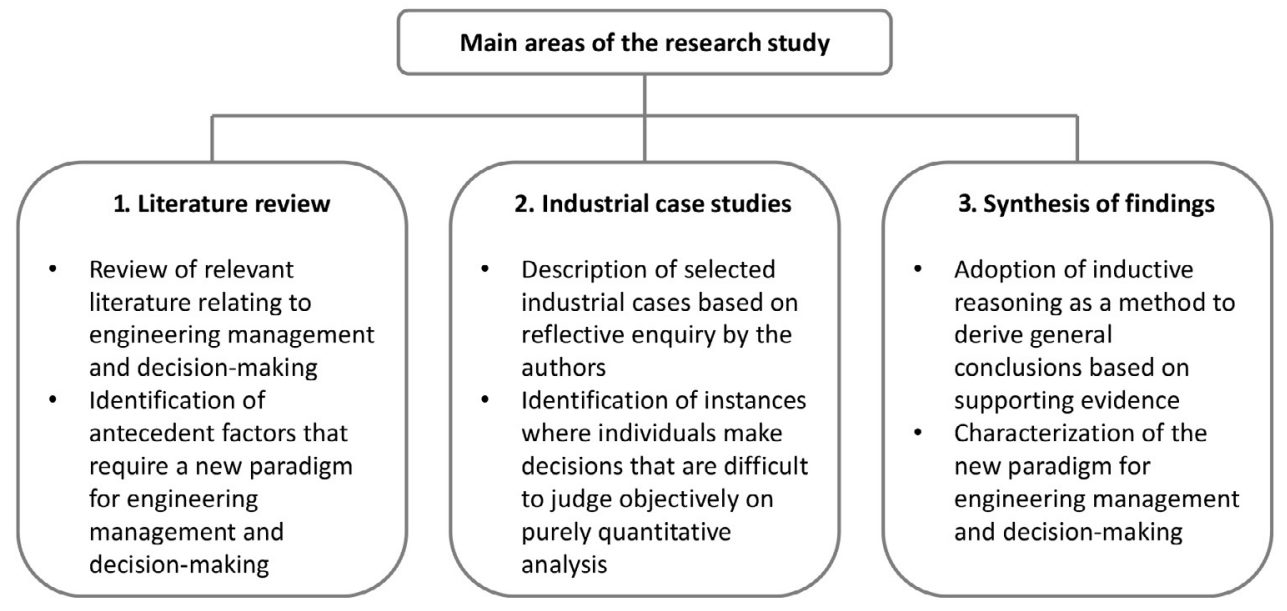

Fig. 1. Methodological scheme for the research study

(Fig. 1). The method is composed of three main stages, which are as follow: a literature review (1); industrial case studies (2); and synthesis of findings (3). This approach allows for considering relevant and pertinent literature to determine the key antecedent factors that require the adoption of a new paradigm for engineering management and decisionmaking. This position is explored through reflection of a series of industrial cases using the participatory action research method and a process of inductive reasoning to allow synthesis of generalised propositions that are linked to the industrial cases and antecedent factors from the literature.

\section{INDUSTRIAL CASE STUDIES}

Through their careers, the authors have been exposed to the inner workings of more than 50 organisations. There have been instances where they were fortunate to witness details that would not be available to an investigator performing a specific study as an outsider. For example, one of the authors was in a planning meeting where certain expertise in high voltage harmonics was established as needed. The experts in the room were able to identify only one person in the geographic region (population of circa 5 million) who had the necessary skill to do the required work. They proceeded to negotiate with the worker's current employer to have the worker seconded for the duration of the design schedule. These situations emerge when a very specific skillset is required. However, the authors contend that workers with rare special skills can be found for almost any job type. These are the type of workers who can make decisions that will greatly impact organisational per- formance. Nevertheless, these workers are also rare. At one conference attended by one of the authors, a keynote speaker speculated that exceptional workers with performance-changing skills represent around 1 in 300 workers. The authors assume that people having such skills can also use them. From the experience of the authors with many different industrial organisations, and looking deeply among the ranks, such workers are available at a frequency of around 1 in 100. It is disappointing to note that these people are too often unrecognised by management as being special and are either passed over for key positions or among the first to be let go in a downturn (Kennedy \& Huston, 2012).

It is useful to consider a series of industrial cases to advance the analysis of opportunities to positively impact the role of engineering management and decision-making processes. The data for the examples that follow are taken from first-hand encounters with the participants, using the participatory action research method (Chevalier \& Buckles, 2019). In each case, at least one of the authors was involved within the primary industrial organisation for a longer-term service (i.e., a minimum of several months). The observations recorded were not the focus of the work within the organisations, but rather were extracted here due to similarities of the situations relative to the subject matter being presented. All representations of the events are from first-hand involvement in the work being observed and direct discussions with the participants.

\subsection{CASE I: RECOGNISING AN OPPORTUNITY WITH SIGNIFICANT IMPACT}

The first case involved an EPC (engineering, procurement and construction) company hired to 
design and build a process plant for an operating company. A part of the design involved numerous piping runs. The design process involved best practice stages with supervision by experienced engineers, interdisciplinary reviews, approvals by owner company engineers at various stages of design maturity and final engineer stamped drawings issued for construction.

Along with the physical design, there were process calculations, operations modelling and control logic programming. This process involved more than 100 people. At no point were any reservations raised in the proposed design. However, a part of the design proposed 14-inch piping, including fittings and valves. When a project engineer assigned to the construction of the approved facility was requested to approve the purchase order for the 14-inch valves, she raised a flag about the appropriateness of the sizing. The experienced procurement officer noticed nothing unusual because three quotes were received for the material, and the lowest was selected. The project engineer, however, was aware that 14 -inch piping was not a "common" size. The design engineers selected the "standard" 14 -inch sizes but herein lies the difference. Although many of the people involved in the project to this point were fully experienced in similar engineering projects, none were ever sufficiently required to consider the financial impact of their decisions.

A summary review of published literature on optimising piping designs found the inclusion of 14-inch piping as a "standard" size and an equally viable choice as 12-inch and 16-inch piping (e.g., Akbarnia, Amidpour \& Shadaram, 2009). Only a rare team member who has looked at the financial impact of such decisions would know that 14 -inch piping is not "common". Deviating from what is typically used, such as selecting an uncommon piping size, can have a significant and unexpected impact on the cost (Fig. 2). Once the impact of the choices was highlighted by the project engineer, modifications to the design were made substituting 12-inch valves along with other engineering changes to accommodate the hydraulic impacts. The installed cost of the project was reduced by USD 120000 , or $2 \%$ of the total project cost. In an industry where average profit margins on such projects are typically less than 5\% (Silva, 2014), such savings have a notable impact on the viability of the engineering company. Again, the issue was not technically complex, but the improvement was not apparent to the first hundred people involved. It is also notable that the engineer who identified the recommended change had to expend several hours demonstrating to the other team members that the point was valid. It is also notable that a slowdown in the engineering company subsequent to these events resulted in the layoff of approximately $5 \%$ of the staff and the project engineer who identified the opportunity was one of those let go. This is offered to suggest that management may not recognise the value of such a person within their organisation.

The relevant highlights of Case I are as follow: i) a team of more than 100 people developed a plan according to their accepted work methods; ii) one person offered a more cost-effective alternative; iii) the group at large required convincing of the validity of the proposal; and iv) senior management appeared to not recognise the value of this individual.

\section{Gate Valves (class PN20)}

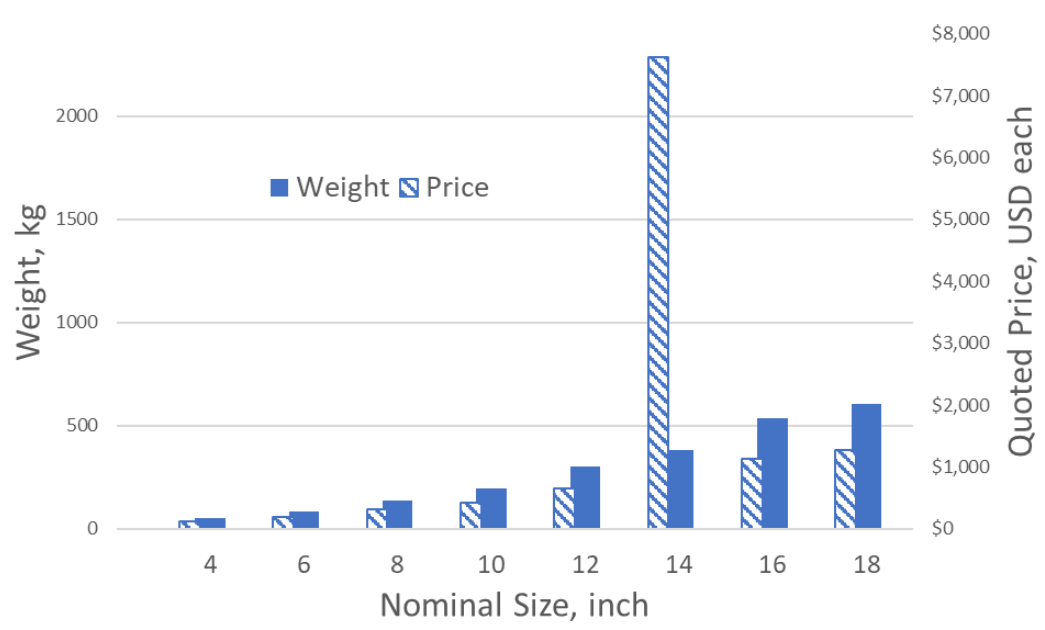

Fig. 2. Comparison of price vs weight for standard valve sizes 


\subsection{CASE II: THE IMPACT OF NOT CLEARLY UNDERSTANDING A SYSTEM}

The authors contend that the types of potential benefits from Case I are more common than senior management may understand or at least acknowledge within their organisation. To demonstrate, the authors provide further illustrative examples from their industrial experiences of identifying how key individuals who have a better understanding of the factors leading to success can greatly influence outcomes. A second case involved a situation where a company decided to adopt a new ERP (enterprise resource planning) process and data management system for improved tracking of the company's history. One technology expert offered a personal opinion that the existing data could not be easily uploaded into the new ERP system, and a conversion effort was required to convert the data into a more compatible format. After expending around USD 500000 in data conversion, an outsider to the process discovered what was being done and pointed out that the internal expert made an error as the new system had the ability to easily absorb the existing data without the conversion step.

The relevant highlights of Case II are as follow: i) an established company with thousands of employees implemented a change in knowledge work processes; ii) the in-house expert in the digital information system made a decision based on experience that needlessly expended important resources; iii) no one else in the organisation recognised the inefficiency; and iv) the management did not appear to acknowledge any suboptimal performance.

\subsection{CASE III: THE LASTING IMPACT OF PLANT INFRASTRUCTURE DECISIONS}

A third case relates to the expansion of a chemical company's operations through the development of a new storage system consisting of tankage to store liquids. The company recognised the potential for further expansion and acquired the real estate to double the number of tanks from four to eight, as shown in Fig. 2. The design team decided to place the pumps used to transfer the liquids close to the main road. Five years after the engineering facility was designed, approval was received to proceed with the expansion. The head engineer, relatively new to the company, reviewed the scope and pondered why the pumps were not placed in the middle of the eight tanks instead of at one end. The pumps do not have the ability to draw the liquid from the required distance. Adding a second set of pumps cost the company circa USD 2 million, an expenditure that would not have been necessary if they were placed as shown in the right side of Fig. 3. Such an approach was not considered at the time of the original design but had someone been on the project team who better understood engineering design, the improved design would have been selected.

As with Case II, Case III involves a decision that has significant operating and capital impacts. The highlights can be summarised as follow: i) a fully qualified and certified design team is used to design new plant infrastructure; ii) a fully qualified in-house worker evaluates the proposed design and determines a suitable location for facilities that meets all the current requirements; iii) an equally qualified person

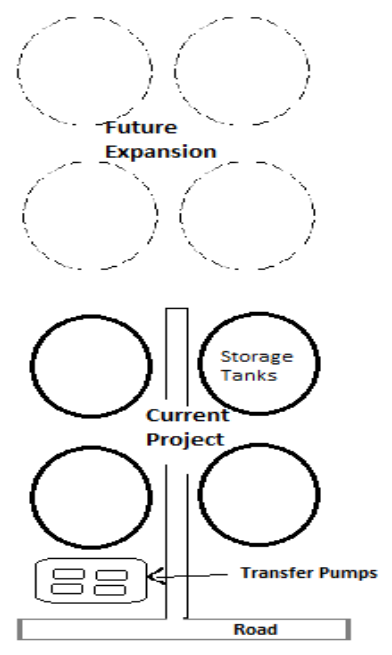

PROJECT AS CONSTRUCTED

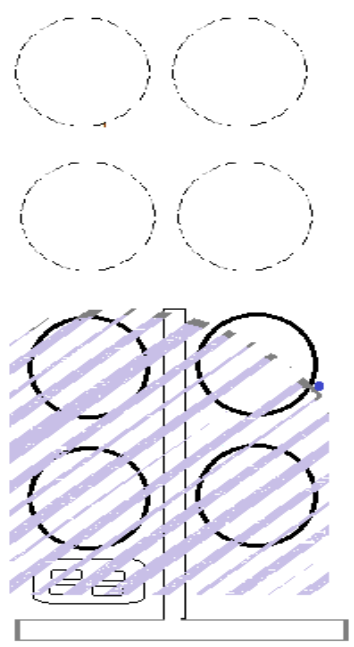

EFFECTIVE RANGE OF TRANSFER PUMPS

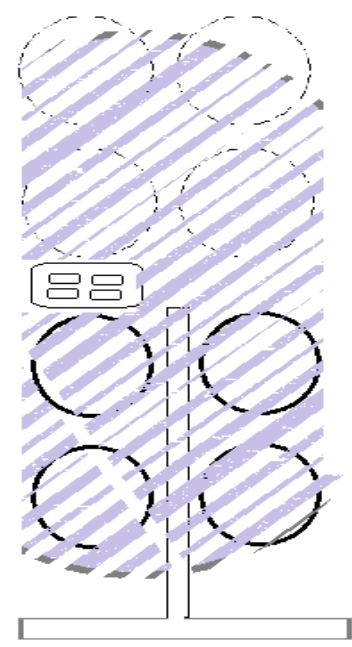

BETTER PLACEMENT OF PUMPS

Fig. 3. Case of pump placement 
then identifies how a better decision could have been made that improves operation and avoids significant future costs; and iv) the management did not acknowledge any lessons learned from the new revelations.

\subsection{CASE IV: THE LASTING IMPACT OF ONE- TIME DECISIONS}

A fourth case involved two competing open-pit mining companies, $\mathrm{A}$ and $\mathrm{B}$, which have been operating for several decades in geographic proximity. A review of the financial reports indicates that Company A consistently has $10 \%$ lower operating costs than Company B. In speaking to geologists at both companies, they acknowledged that the difference is largely due to the locations selected for the mines. The original chief geologist for Company A selected regions to acquire where the amount of soil required to be removed was minimal. The chief geologist for Company B selected regions where the ore was richer in the product. The savings from moving much less soil gave Company A an advantage of several million dollars annually over its closest rival.

Case IV highlights Herzberg's contention that the initial design decisions can have a much greater impact on organisational viability than any of the motivational policies he championed. The relevant elements of this case can be summarised as follow: i) both companies had hundreds of engineers and support staff involved in the initial design of their facilities; ii) each company proceeded on a slightly different path in selecting the locations for their plants using fully trained and qualified people; iii) after years of operation, the decisions made by a key person proved to be significantly better for profits compared to the competing design team; and iv) published financial statements and analyses by neither company recognised the fundamental difference in the decision made at the time of design and how this affected the relative performances of the two companies.

\subsection{CASE V: IMPACT FROM A SINGLE PERSON DEVIATING FROM PRESCRIBED POLICY}

The fifth case involves a situation where a company incorporates advanced automation into its manufacturing assembly line, and an unfortunate fire destroyed a section of the control equipment. It was estimated that it would take about eight weeks to complete repairs to the stage where the hardware cards will be needed to be reinstalled into the control panels. The project engineer directed the purchaser to obtain the cards in four weeks to assure they arrived in time with a healthy buffer. Aiming to adhere to company protocols, the request was made explicitly by a required form, where the required date was entered as a single cell that does not allow for any leeway in the form of a range. The procurement team held vendors to the four-week deadline. This required substitution of the specified cards with another more readily available model that would provide a suboptimum solution allowing the plant to restart but with less than the desired performance. The team changed plans to accommodate the new direction, but one team member on the design team decided to telephone the vendor. It was discovered that the proper cards would be available in six weeks (within the time available to reinstall on schedule), but the vendor was not told there was some flexibility in the delivery schedule. Although the inquisitive team member was reprimanded for overstepping their area of responsibility, the company followed through with buying the desired cards. If that one team member had not taken the initiative (knowing the reprimand might come), the company would have gone down the less desirable path.

The relevant elements of Case V are as follow: i) a fully qualified and experienced team of company employees is executing a project; ii) one person oversteps their assigned duties to challenge the decision made by the team; iii) the alternate is shown to have an advantageous outcome; and iv) despite an improved outcome, the employee is reprimanded by management for not following the company policy.

\subsection{CASE VI: NARROW FOCUS DRIVING DECI- SIONS WITH LONG-TERM IMPACTS}

The sixth and final case is based on a designer with decades of experience drawing P\&IDs (piping and instrumentation diagrams), who is asked for their opinion on two alternatives for a particular engineering layout and operating philosophy. The designer recommended the option that would require 40 hours to draw, noting the other option would require 160 hours to draw. When the drawings were completed, they were sent for review by several stakeholder groups. After being approved by most of the stakeholders, one operations worker noted that a solution equivalent to the rejected alternative is better because it would save an estimated USD 200000 a year in operating costs and be simpler to maintain. The operations worker championed the alternate 
design and won over support for the improved design, including some dissension by the design team. The designer was then instructed to go back and produce a new set of drawings in line with the originally rejected proposal.

The elements of Case VI which parallel the previous cases are as follow: i) a fully qualified and experienced expert on design makes a decision; ii) a company with hundreds of engineers on staff reviews and accepts the decision with no questions on the design; iii) one person without experience in design offers a beneficial alternative; iv) the better alternative is not accepted immediately and encounters resistance; and v) no specific lesson was documented, or any change to company design standards was made.

\subsection{Cross-CASE ANAlysis}

Following the recommendations of Yin (2002), a cross-case analysis is provided in Table 1 . The key elements from the summaries of each case are shown in tabular form to emphasise the points being illustrated.

These cases from the industry are offered as examples of situations that have been encountered many times by the authors. As shown, many people are often fully communicated to make sure that engineering plans reach a wide set of reviewers. However, there is a small number of people whose involvement is necessary for the best choices to be made. The examples from the industry do not require a specialised area of expertise from a technical or quantitative perspective. But there is a requirement for the individual to have a more complete or systemic understanding of the success factors for the enterprise. Further, the adoption of an integrated systems view of project can allow engineers to be aware of a broader set of factors to be considered when overseeing the delivery of complex engineering projects, namely, process, technology, resources, impact, knowledge and culture (Philbin \& Kennedy, 2014). Engineers able to display such a systemic perspective will benefit from considering the full range of factors and issues to be addressed when designing complex systems and engineering projects and, thereby, avoiding so-called "stove pipe" behaviour of specialists (Ireland et al., 2010), which can lead to negative outcomes associated with a reduced selection of options. Indeed, management guru Tom Peters identified a problem in modern organisations by creating a narrow focus in their workers with the result that specialists are encouraged to control a small portion of the overall operation without learning the impact it has on other departments (Kennedy, 2015). However, the high employee turnover rates now experienced in the 21st century (Cohen, Blake \& Goodman, 2016), provide some opportunities mostly ignored by management studies of a few decades ago, as noted above. Firstly, managers now have many more opportunities to hire the type of special individuals identified in our exam-

Tab. 1. Cross-case analysis

\begin{tabular}{|c|c|c|c|c|c|c|c|}
\hline No. & ELEMENT OF INTEREST & $\begin{array}{c}\text { CASE } \\
1\end{array}$ & $\begin{array}{l}\text { CASE } \\
\text { II }\end{array}$ & $\begin{array}{c}\text { CASE } \\
\text { III }\end{array}$ & $\begin{array}{l}\text { CASE } \\
\text { IV }\end{array}$ & CASE & $\begin{array}{l}\text { CASE } \\
\text { VI }\end{array}$ \\
\hline 1 & $\begin{array}{l}\text { Is the initial decision-maker fully qualified and experienced in } \\
\text { the role? }\end{array}$ & $Y$ & $Y$ & $Y$ & $Y$ & $Y$ & $Y$ \\
\hline 2 & $\begin{array}{l}\text { Does the decision have an impact greater than one year of the } \\
\text { salary of the decision-maker? }\end{array}$ & $Y$ & $Y$ & $\mathrm{Y}$ & $Y$ & $Y$ & $Y$ \\
\hline 3 & $\begin{array}{l}\text { Was the initial decision reviewed by competent personnel and } \\
\text { accepted? }\end{array}$ & $Y$ & $Y$ & $Y$ & $Y$ & $Y$ & $Y$ \\
\hline 4 & $\begin{array}{l}\text { Does the person providing a better alternative have better iden- } \\
\text { tifiable qualifications or experience than the original decision- } \\
\text { maker? }\end{array}$ & $\mathrm{N}$ & $\mathrm{N}$ & $\mathrm{N}$ & $\mathrm{N}$ & $\mathrm{N}$ & $\mathrm{N}$ \\
\hline 5 & $\begin{array}{l}\text { Was there a need for complicated mathematical calculations to } \\
\text { identify the potential benefit? }\end{array}$ & $\mathrm{N}$ & $\mathrm{N}$ & $\mathrm{N}$ & $\mathrm{N}$ & $\mathrm{N}$ & $\mathrm{N}$ \\
\hline 6 & Is the alternative identified in time to take corrective actions? & $\mathrm{Y}$ & $\mathrm{N}$ & $\mathrm{N}$ & N.A. & Y & Y \\
\hline 7 & $\begin{array}{l}\text { Was there visible recognition by management that the person } \\
\text { providing the beneficial alternative was providing unique and } \\
\text { valuable tacit knowledge? }\end{array}$ & $\mathrm{N}$ & $\mathrm{N}$ & $\mathrm{N}$ & $\mathrm{N}$ & $\mathrm{N}$ & $\mathrm{N}$ \\
\hline 8 & $\begin{array}{l}\text { Was there visible recognition by management that would indi- } \\
\text { cate an improved decision-making process going forward? }\end{array}$ & $\mathrm{N}$ & $\mathrm{N}$ & $\mathrm{N}$ & $\mathrm{N}$ & $\mathrm{N}$ & $\mathrm{N}$ \\
\hline
\end{tabular}


ples. Secondly, the succession of jobs now experienced by engineering workers provides the potential to be exposed to many more circumstances and chances to learn perspectives that can be beneficial in new situations. A caution is noted here that in some of the examples reported, the workers who proposed the beneficial changes met resistance and did not receive recognition by their management or were even reprimanded in one case.

\section{TOWARDS A NEW PARADIGM FOR ENGINEERING MANAGEMENT AND DECISION-MAKING IN TECH- NOLOGY-BASED ORGANISATIONS}

It can be observed from the aforementioned cases from the industry that engineers, of course, need the required skills and knowledge (Litzinger et al., 2011) gained through engineering education and subsequent on-the-job training. This includes the quantitative and mathematical skills and knowledge associated with engineering as well as other engineering aspects, such as engineering design, control engineering, materials engineering, etc. Engineers that transition into management also need to have a thorough understanding of the tools and techniques associated with managing systems, people and projects (Mitchell et al., 2019), such as organisational design, team leadership, project management and engineering economics (Philbin et al., 2019). But, crucially, there is also a need to know when to be intuitive in selecting the course of action. Such an intuition, while being guided by having the engineering and engineering management skills and knowledge, should also be a function of experience and akin to "following your gut" for a particular engineering management decision.

The question arises, how can technology-based organisations prepare for such situations? The answer is not straightforward. Essentially, organisations need to accept that following procedures, conducting quantitative assessments and adhering to sets of key performance indicators (KPIs) will only work to a point. In the absence of management controls, implementing a balanced scorecard can help the management to improve operational performance and ensure operations remain aligned with organisational strategy (Kaplan \& Norton, 1996). However, there is still a need for judgement to be applied by the management. This judgement may be in the form of which KPIs are given the highest priority on achieving, or it may be a more subtle form of judgement, such as understanding how to engage stakeholders in the development of the KPIs.

Organisations can raise awareness of the benefits of adopting this holistic approach to decision-making (Savory \& Butterfield, 1998), by deploying standardised and numerical-based decision frameworks alongside more intuitive and judgement-based approaches. Engineering companies can institute strategies to support how to tackle this situation. This could be in the form of workshops that seek to share experience and learning from projects. These projects would highlight how the standardised procedures and numerical assessments need to be balanced against experience-based judgements that are not always the most logical next steps. However, the projects would act as case studies that would share the learnings and drive forward best practice in organisational and project decision-making. Additionally, knowledge management systems can be implemented (Maier \& Hadrich, 2011). The frequently encountered challenge with knowledge management is how to capture tacit knowledge. The capture of explicit, technical data and information is relatively easy. But capturing tacit knowledge built up over many years by knowledge-based workers is particularly difficult. However, if an effective knowledge management system can be implemented, then it may be possible to capture the experience-based insights and knowledge that can feed into future project decisions that require experience-based inputs to be considered alongside the numerical frameworks.

A supporting culture will be required to implement the aforementioned approaches, and this culture will need to accommodate risk and reward for the knowledge workers if they are to feel comfortable to take project decisions that incorporate judgement alongside numerical decision frameworks. In this regard, senior management will need to be supportive (Ribiere \& Sitar, 2003) through ensuring a collaborative culture allows the organisations to effectively learn from project successes and also from mistakes. Indeed, existing project management processes stipulate that a project lessons learnt review should take place after a project has been completed and the key findings from the project should be captured and stored so that projects in the future can benefit from the insights generated from the project (Carrillo et al., 2013). However, all too often at the end of a project, the project team members move on to other projects and in some cases, even move on to other 
organisations before the lessons learnt can be captured. Instead, a log of lessons learnt should be kept throughout the project so as to avoid this situation. Moreover, such project lessons learnt need to be integrated into the knowledge management system so that the knowledge and insights on delivered projects are available with explicit and other forms of tacit knowledge to improve organisational and project level decision-making (Collins, 2010).

Ultimately there is a need for organisations to leverage all available resources, including the physical as well as non-physical or intangible resources (Mahoney \& Pandian, 1992). Industrial companies can in some cases be adept at managing physical resources (such as infrastructure, equipment, materials as well as capital; provision), but they can be less effective at successfully managing the contributions of knowledge workers. If organisations and engineering projects are to be more effective in implementing decision-making frameworks that incorporate judgement as well as numerical assessments, facilitated by efficient knowledge management and a supportive culture, there will need to be improvements in how organisations harness the contributions of the knowledge workers.

\section{CONCLUSIONS}

The research study reported in this article has explored the need for a new paradigm for engineering management and the decision-making process. This has been enabled through consideration of key areas of the academic literature as well as drawing on the insights gained from a series of industrial cases. As a part of a process of inductive reasoning, the findings of the research study have been synthesised to identify the new paradigm for engineering management and the decision-making process. This includes several areas, which are as follow: the need for engineering managers to have enhanced professional skills and knowledge; the importance of experiencebased judgement; effective knowledge management; supportive leadership and overall organisational culture; and a holistic approach to decision-making.

The authors contend that the industrial cases provided in this article are common enough and an organisation that directs resources towards the enhancement of decision-making processes can have significant improvements in viability. It should also be noted that the knowledge contained by engineers who were able to identify improvement opportunities did not involve complex calculations requiring years of study of advanced subjects. Therefore, the authors propose that the management should be able to cultivate engineers who could step up in such circumstances to help direct proper stewardship and, thereby, more effective decision-making. In this context, it will be important for engineering managers to have access to the required skills and knowledge that moves beyond the traditional background in quantitative methods. This enhanced set of skills includes people and social related abilities and awareness and can be viewed in relation to EQ or emotional quotient (Bar-On et al., 2004), i.e. an ability to manage emotions through positive engagement with others and through effective communication to address challenges that may arise.

We must also note that this is not an issue helped by most typically offered tools intended to assist engineering managers in improving performance. In all the industry cases covered, quantitative measures would not flag any problem with decisions being made. Deming often highlighted how the important factors for success were not quantifiable. In this vein, there is much literature demonstrating how quantitative measures, such as KPIs, that may lead to behaviours that are actually opposite to the outcomes intended to be supported (Paul-Hus, Desrochers, De Rijcke, \& Rushforth, 2017) or even manipulation to cloud issues that may deserve management action (Demski, 1998). Indeed, Kennedy and Huston (2012) provide the case where one project manager was seen by upper management as being a top performer because his projects were consistently under budget. However, the researchers highlighted that by adopting a longer-term perspective, the engineer was able to secure higher budgets to make it easier to come in under the budget. Other project managers completed similar engineering projects spending much less, but only meeting or slightly exceeding their negotiated budgets. Looking at a sample of very similar projects, the top performer spent in excess of USD 2 million more than the other project managers for similar scopes. As a consequence of focusing on performance against negotiated budget, management rewarded the project manager's skill in effectively gaming the system rather than their overall ability to steward resources.

Future work is suggested to focus on a detailed investigation of the decision-making process that is currently adopted by engineering managers. In this regard, longitudinal research studies are recommended that examine the decision-making processes 
in industrial engineering companies; international comparative studies are also suggested as an informative empirical mechanism to reveal greater insights in this area. Finally, it is suggested that future research is directed towards understanding the impact of increasing levels of digitalisation on the decisionmaking process as well as identification of the tools and techniques available to engineering managers in this context.

\section{LITERATURE}

Afonasova, M. A., Panfilova, E. E., Galichkina, M. A., \& Ślusarczyk, B. (2020). Digitalization in economy and innovation: The effect on social and economic processes. Polish Journal of Management Studies, 19(2), 22-32.

Aguinis, H., Gottfredson, R. K., \& Joo, H. (2012). Using performance management to win the talent war. Business Horizons, 55(6), 609-616.

Akbarnia, M., Amidpour, M., \& Shadaram, A. (2009). A new approach in pinch technology considering piping in total cost targeting for heat exchanger network. Chemical Engineering Research and Design, 87(3), 357-365.

Baker, S. R., Bloom, N., Davis, S. J., \& Terry, S. J. (2020). Covid-induced economic uncertainty (No. w26983). National Bureau of Economic Research.

Balzer. W. K., \& Smith, P. K. (1990). User's manual for the Job Descriptive Index (JDI) and the Job in General (JIG) Scales. Bowling Green University.

Bar-On, R., Tranel, D., Denburg, N. L., \& Bechara, A. (2004). Emotional and social intelligence. Social Neuroscience: Key Readings, 223, 52.

Carrillo, P., Ruikar, K., \& Fuller, P. (2013). When will we learn? Improving lessons learned practice in construction. International Journal of Project Management, 31(4), 567-578.

Carson, K. P., Cardy, R. L., \& Dobbins, G. H. (1991). Performance appraisal as effective management or deadly management disease: Two initial empirical investigations. Group and Organization Studies, 16(2), 143-159.

Chesbrough, H. (2002). Graceful exits and missed opportunities: Xerox's management of its technology spin-off organizations. Business History Review, 76(4), 803837.

Chevalier, J. M., \& Buckles, D. J. (2019). Participatory action research: Theory and methods for engaged inquiry. Routledge, Taylor \& Francis Group.

Cohen, G., Blake, R. S., \& Goodman, D. (2016). Does turnover intention matter? Evaluating the usefulness of turnover intention rate as a predictor of actual turnover rate. Review of Public Personnel Admin, 36(3), 240-263.

Collins, H. (2010). Tacit and explicit knowledge. University of Chicago Press.

Demski, J. S. (1998). Performance measure manipulation. Contemporary Accounting Research, 15(3), 261-285.
Diamond Jr, A. M. (2019). Openness to creative destruction: Sustaining innovative dynamism. Oxford University Press.

Drucker, P. (1959), The Landmarks of Tomorrow, New York: Harper \& Row.

Elbanna, S. (2006). Strategic decision-making: Process perspectives. International Journal of Management Reviews, 8(1), 1-20.

Fayol, H. (1918). Administration industrielle et générale (Vol. 2). Dunod et Pinat.

Fisher, J. G. (1998). Contingency theory, management control systems and firm outcomes: past results and future directions. Behavioral Research in Accounting, $10,47$.

Fox, J. (2009). The myth of the rational market: A history of risk, reward, and delusion on Wall Street. New York: Harper Business.

Gabor, A., \& Tarrant, J. (1990). The man who discovered quality: How W. Edwards Deming brought the quality revolution to America: The stories of Ford, Xerox, and GM. New York: Times Books.

Gavetti, G. (2004). Kodak (A) Volume 9 of Harvard Business School case studies, Harvard Business School.

Hazlett, S. A., McAdam, R., \& Gallagher, S. (2005). Theory building in knowledge management: in search of paradigms. Journal of Management Inquiry, 14(1), $31-42$.

Herzberg, F. I. (1966). Work and the Nature of Man. The World Publishing Company.

Hovnanian, G., Kroll, K., \& Sjödin, E. (2019). How analytics can drive smarter engineering and construction decisions. McKinsey \& Company Capital Projects \& Infrastructure.

Ireland, V., Croser, P., \& Croser, S. (2010). Moving organisations from a systems engineering approach to a System of Systems approach. Proceedings of the 8th Conference on Systems Engineering Research, New Jersey, USA: Hoboken.

Kaplan, R. S., \& Norton, D. P. (1996). Linking the balanced scorecard to strategy. California Management Review, 39(1), 53-79.

Kennedy, D. (2010). Flogging the Innocent: Higher Profits, Great Ethics, Enjoyable Work. Edmonton: Freerange Buddy Publications.

Kennedy, D. (2015). What if the Gurus Were Right?: Part III. In Proceedings of the International Annual Conference of the American Society for Engineering Management. American Society for Engineering Management (ASEM).

Kennedy, D., \& Huston, M. (2012). Don't promote the villains-A closer look at proper metrics helps uncover those who game the system. Industrial Engineer, 44(10), 28.

Kennedy, D., \& Nur, M. (2012). The rise of taylorism in knowledge management. 2012 Proceedings of PICMET'12: Technology Management for Emerging Technologies, IEEE, 2283-2289.

Kennedy, D., \& Philbin, S. P. (2018). The imperative need to develop guidelines to manage human versus machine intelligence. Frontiers of Engineering Management, 5(2), 182-194. 
Kerzner, H. (2017). Project management: a systems approach to planning, scheduling, and controlling, 12th edition. John Wiley \& Sons.

Ketokivi, M., \& Mantere, S. (2010). Two strategies for inductive reasoning in organizational research. Academy of Management Review, 35(2), 315-333.

Koontz, H. (1961). The management theory jungle. Academy of Management Journal, 4(3), 174-188.

Koschmann, T. (1996). Paradigm shifts and instructional technology: An introduction. CSCL: Theory and practice of an emerging paradigm, 116, 1-23.

Krykavskyy, Y., Pokhylchenko, O., \& Hayvanovych, N. (2019). Supply chain development drivers in industry 4.0 in Ukrainian enterprises. Oeconomia Copernicana, 10(2), 273-290. doi: 10.24136/oc.2019.014

Kuhn, T. S. (1977). Second thoughts on paradigms. In T. S. Kuhn (Ed.), The Essential Tension (pp. 293-319). Chicago: University of Chicago Press.

Lannes, W. J. (2001). What is engineering management?. IEEE Transactions on Engineering Management, 48(1), 107-115

Litzinger, T., Lattuca, L. R., Hadgraft, R., \& Newstetter, W. (2011). Engineering education and the development of expertise. Journal of Engineering Education, 100(1), 123-150.

Lucia, S., Kögel, M., Zometa, P., Quevedo, D. E., \& Findeisen, R. (2016). Predictive control, embedded cyberphysical systems and systems of systems-A perspective. Annual Reviews in Control, 41, 193-207.

Mahoney, J. T. \& Pandian, J. R. (1992). The resource-based view within the conversation of strategic management. Strategic Management Journal, 13(5), 363-380.

Maier, R., \& Hadrich, T. (2011). Knowledge management systems. Encyclopedia of Knowledge Management, Second Edition, IGI Global, 779-790.

McGuire, J. W. (1982). Management theory: Retreat to the academy. Business Horizons, 25(4), 31-37.

McGure, J.W. (1982). Management theory: Retreat to the academy. Business Horizons, Jul/Aug 1982, 31-37.

Mintzberg, H. (1973). The Nature of Managerial Work. Engle-wood Cliffs.

Mitchell, J. E., Nyamapfene, A., Roach, K., \& Tilley, E. (2019). Faculty wide curriculum reform: the integrated engineering programme. European Journal of Engineering Education, 1-19.

Nittala, S., \& Jesiek, B. K. (2018). Work Experiences of Engineering Managers: Challenges, Strategies, Competencies. 2018 IEEE Frontiers in Education Conference (FIE), IEEE, 1-4.

Nwaiwu, F., Duduci, M., Chromjakova , F., \& Otekhile, C.-A. F. (2020). Industry 4.0 concepts within the Czech SME manufacturing sector: an empirical assessment of critical success factors. Business: Theory and Practice, 21(1), 58-70. doi: 10.3846/ btp.2020.10712

Parviainen, P., Tihinen, M., Kääriäinen, J., \& Teppola, S. (2017). Tackling the digitalization challenge: how to benefit from digitalization in practice. International Journal of Information Systems and Project Management, 5(1), 63-77.
Paul-Hus, A., Desrochers, N., De Rijcke, S., \& Rushforth, A. D. (2017). The reward system of science. Aslib Journal of Information Management, 69(5), 478-485.

Peters, T. J. (2004). A skunkworks tale. The Stanford Magazine 1983, Reprinted in the Human Side of Managing Technological Innovation: A Collection of Readings, 405-413.

Phelps, L. D., Parayitam, S., \& Olson, B. J. (2007). Edwards Deming, Mary P. Follett and Frederick W. Taylor: Reconciliation of differences in organizational and strategic leadership. Academy of Strategic Management Journal, 6.

Philbin, S. P. (2008). Managing complex technology projects. Research-Technology Management, 51(2), 32-39.

Philbin, S. P., \& Kennedy, D. A. (2014). Diagnostic framework and health check tool for engineering and technology projects. Journal of Industrial Engineering and Management, 7(5), 1145-1166.

Philbin, S. P., Kauffmann, P., \& Wyrick, D. A. (2019). Engineering Education, Skills and Industry Alignment-Comparative Analysis of the UK and USA. Proceedings of the International Annual Conference of the American Society for Engineering Management, Philadelphia (PA) USA. American Society for Engineering Management (ASEM), 1-11.

Rana, T. M., Salaria, M. R., Herani, G. M., \& Amin, M. (2009). Identifying factors playing important role in the increasing employees' turnover rate: A case of telecom industry in Pakistan. Industrial Journal of Management \& Social Sciences, 3(2), 80-89.

Ribiere, V. M., \& Sitar, A. S. (2003). Critical role of leadership in nurturing a knowledge-supporting culture. Knowledge Management Research and Practice, 1(1), 39-48.

Roethlisberger, F. J., \& Dickson, W. J. (1939). Management and the Worker. Harvard University Press.

Sarchet, B. R. (1989). Engineering Management-Key To The Future. Engineering Management Journal, 1(1), 4-7.

Savory, A., \& Butterfield, J. (1998). Holistic management: a new framework for decision making. Island press.

Siderska, J. (2020). Robotic Process Automation- a driver of digital transformation? Engineering Management in Production and Services, 12(2), 21-31.

Silva, A. F. R. (2014). Bankruptcy forecasting models civil construction. Doctoral dissertation Universitário de Lisboa.

Sim, G. (2016). Individual Disruptors and Economic Gamechangers: Netflix, New Media, and Neoliberalism. The Netflix Effect: Technology and Entertainment in the 21st Century. (pp. 185-202). London and New York: Bloomsbury Academic.

Slocum, J. (2006). Grooming for the top post and ending the CEO succession crisis. Organizational Dynamics, 35(1), 96-105.

Taylor, F.W. (1911). Scientific Management. New York: Harper and Brothers.

Tworek, K., Walecka-Jankowska, K. \& Zgrzywa-Ziemak, A. (2019). Towards organisational simplexitya simple structure in a complex environment. Engineering Management in Production and Services, 11(4), 43-53. 
Upton, D.M. (1998). Designing, Managing, and Improving Operations. Prentice Hall.

Vetrova, E., Doroshenko, S., Tihomirov, N., Khakimova, G., \& Kakava, L. (2020). Model of investment decision-making in a small industrial enterprise. Forum Scientiae Oeconomia, 7(4), 7-23. doi: 10.23762/FSO_ VOL7_NO4_1

Wolff, L. (2008). The death of lifelong employment in Japan. Corporate governance in the 21st century: Japan's gradual transformation, Cheltenham: Edward Elgar.

Xu, L. D., Xu, E. L., \& Li, L. (2018). Industry 4.0: state of the art and future trends. International Journal of Production Research, 56(8), 2941-2962.

Yin, R. K. (2002). Case Study Research: Design and Methods. Thousand Oaks, CA: SAGE Publications.

Zhang, H., Kitchenham, B., \& Jeffery, R. (2007). Planning software project success with semi-quantitative reasoning. 2007 Australian Software Engineering Conference (ASWEC'07), 369-378. 